\title{
Product Sentiment Assessment using Large Scale Cloud System
}

\author{
K.P.Kaliyamurthie
}

\begin{abstract}
A typical manner in which valuable information can be obtained by means of extracting the sentiment or also the opinion from any message is called sentiment analysis. The sentiment classification exploits the technologies in machine learning owing to their ability to learn from training data set to predict and support decision making with high accuracy level. Some algorithms do not maintain proper scalability for large datasets. Today, there are several disciplines that have the need to deal with some big datasets for involving features in high numbers. The methods of feature selection have been aiming at the elimination of the noisy, the irrelevant or the redundant features that can bring down the performance of classification. Most of the traditional methods lack the scalability to be able to cope with the results within a given time. Here in this work, Term Frequency (TF) that is a method of feature extraction has been used. The focus has been on the selection for the opinion mining by using the Information Gain (IG) based method and compared with the method of. All these methods of feature selection have reduced all the original feature sets by means of removing the features that are irrelevant to enhance the accuracy of classification and bring down the running time of the learning algorithms. The method proposed has been evaluated by means of using the Support Vector Machine (SVM) based classifier. The experimental results have proved that the proposed method had achieved better performance.
\end{abstract}

\section{Keywords: Sentiment Analysis, Big Data}

\section{INTRODUCTION}

The Sentiment analysis will be product. The sentiment analysis will include the building of the system for the collection and the examination of the opinions on the product based on the comments, the reviews, the tweets or the blog posts. Sentiment analysis has been used in several ways and this may be like the judging the success of an even in the marketing process. The opinions may be on the consumer goods, movies, books, political issues etc., that have a major influence in the shaping of opinions of the other consumers.Big data has been a research area that is trending in both computer science and sentiment analysis.

For the big data examination, usually industry and academics use Hadoop execution of MapReduce structure. The open source complements of the GFS are Hadoop

Revised Manuscript Received on October 22, 2019.

Dr.K.P.Kaliyamurthie, Professor \& Dean, Department of Computer Science and Engineering, Bharath Institute of Higher Education and Research, Chennai, India
MapReduce and the Hadoop Distributed File System (HDFS).Many projects have been reinforced by Apache Foundation such as:

- HBase - database,

- Hive - data warehouse,

- Pig - high level data-flow,

- Zookeeper - high-performance coordination and

- Mahout -scalable machine learning and its data mining

A feature is that individual measurable property belonging to the very process that has been observed. There are many different techniques that have been developed for addressing this problem of reduction of irrelevant and redundant variables that have proved to be a burden on the tasks that are challenging. The main focus here is to choose a set of different factors form any given that explains the given forms positively efficient and also brings down the effects of the irrelevant or noisy variables.The feature extraction has outperformed the other methods that are state-of-the-art and only all the external resources will be used in the domain. So, this is both generic and also unsupervised. The advent of the extremely high dimensional datasets, have made the techniques of dimensionality reduction mandatory. The Swarm intelligence algorithms have been extensively used rendering the feature subsets by means of improving the accuracy as well as reducing the complexity of computation and the size of the features set.

\section{METHODOLOGY}

Here in this work a subset of the amazon book sentiment dataset (with 45000 Positive, about 40000 negative and about 35000 neutral) have been used. A TF based feature extraction has also been employed for the extraction of features and the IG with the GSO based selection with the SVM based classifier have been discussed.

\section{A.Term Frequency (TF) based Feature Extraction}

The Inverse Document Frequency (IDF) is a defined terms as well as widely in the retrieval of information. Combining of IDF with TF leads to robust and highly effective weighting method is applied to NLP, the knowledge management, the text classification and finally the information retrieval.

A term document frequency has been computed as below for a set of documents and with a set of the terms . Every document has been modeled as the vector within the 
dimensional space. While a TF denoted by a it further expresses the actual number of the occurrence of a term in the document. This TF matrix has measured the value in the given set . is null at a time the value has particular term and when the term occurs in the terms of or makes use of a TF [21] that is the TF and will be against all the total occurrences of the terms of the document. Frequency is normalized as in (1):

$T F(x, a)=\left\{\begin{array}{lr}0 & \text { freq }(x, a)=0 \\ 1+\log (1+\log (\text { freq }(x, a))) & \text { otherwise }\end{array}\right.$

The above expression, will represent the magnifying factor and when the term occurs in various documents, the magnifying factor owing to the lowered power of discrimination. The above expression has been shown in (2):

$$
\operatorname{IDF}(a)=\log \frac{1+|x|}{x_{a}}
$$

being the final set of documents that contain the factor .

In the TF-IDF is used generally in the categorization the sentiment analysis is less known and is used as the unigram feature weight. The TF-IDF will have two scores, the TF and the IDF. The former is counting the number of times any term takes place and the latter is derived by calculating factors the total documents by the details the word repeatedly appears.

\section{B.Information Gain (IG) Based Feature Selection}

Information gain is the feature that measures information got for the prediction class of arbitrary text documents witheither the occurrence or the non-occurrence of features. The IG is then calculated by the involvement of the feature on decreasing the overall entropy. The expected information for classifying the instance (the tuple) for a partition D or to identify a class label of any instance in case of $\mathrm{D}$ is called the entropy and is depicted as in

$$
\operatorname{Info}(D)=\sum_{i=1}^{m}\left(P_{i}\right) \log _{2}\left(P_{i}\right)
$$

In which the $m$ indicates the number of the classes (that is $\mathrm{m}=2$ for the binary classification) and the denotes the probability which is a random instance in the partition $D$ all the instances for every class/category). There is a log function for the base which justifies that the encoded information is in bits. If there has to be a partition (classify) of an instance in the D on feature attributes, the D splits into the $\mathrm{v}$ partitions set. Where the amount of information is in bits, requiring exact classification that is measured as in (4):

$$
\operatorname{Info}_{A}(D)=-\sum_{j=1}^{v} \frac{\left|D_{j}\right|}{|D|} \times \operatorname{Info}\left(D_{j}\right)
$$

In which the $|\mathrm{Dj}| /|\mathrm{D}|$ denotes the weight of the jth partition and the Info ( $\mathrm{Dj}$ ) will be the entropy of the partition $\mathrm{Dj}$. Finally, the IG by dividing A (feature attribute) is (5): which Pertaining to a class function to be (the proportion of

$$
\text { Information Gain }(A)=\operatorname{Info}(D)-\operatorname{Info}_{A}(D)
$$

It chooses the features that are ranked as according to a high IG score and this can optimize the required information and the overall entropy by classifying them.

The GSO population [25] is known as a group where each individual in a population is known to be a member. In case of an n-dimensional search space, an ith member at a kth searching about (the iteration), will have a current position $\quad X_{i}^{k} \in R^{n} \quad$ and $\quad$ a $\quad$ head angle $\varphi_{i}^{k}=\left(\varphi_{i_{1}}^{k}, \ldots, \varphi_{i_{(n-1)}}^{k}\right) \in R^{n-1}$ with a head direction $D_{i}^{k}\left(\varphi_{i}^{k}\right)=\left(d_{i_{1}}^{k}, \ldots, d_{i_{n}}^{k}\right) \in R^{n}$ that may be calculated suing $\varphi_{i}^{k}$ through the Polar to the Cartesian co-ordinates transformation as per (6):

$$
\begin{aligned}
& d_{i_{1}}^{k}=\prod_{q=1}^{n-1} \cos \left(\varphi_{i_{q}}^{k}\right) \\
& d_{i_{j}}^{k}=\sin \left(\varphi_{i_{(j-1)}^{k}}^{k}\right) \cdot \prod_{q=j}^{n-1} \cos \left(\varphi_{i_{q}}^{k}\right) \quad(j=2, \ldots, n-1) \\
& d_{i_{n}}^{k}=\sin \left(\varphi_{i_{(n-1)}^{k}}^{k}\right) .
\end{aligned}
$$

At every such member location, the function of fitness is duly evaluated and among members the one that minimum value) is chosen to be the producer. This producer performs scanning randomly choosing the and on of the producer in (7).

$$
\begin{aligned}
& X_{z}=X_{p}^{k}+r_{1} l_{\max } D_{p}^{k}\left(\varphi^{k}\right) \\
& X_{r}=X_{p}^{k}+r_{1} l_{\max } D_{p}^{k}\left(\varphi^{k}+r_{2} \theta_{\max } / 2\right)
\end{aligned}
$$

In which the denotes a random number that has a standard normal distribution (the mean 0 and the standard deviation 1) and the being a random sequence within a range $(0,1)$.

$$
\varphi^{k+1}=\varphi^{k}+r_{2} \alpha_{\max }
$$

In which the is a cannot get a better area after the $a$ iterations, it turns back to the zero degree. All the scroungers join the resource of producers, to perform a scrounging strategy (9):

$$
X_{i}^{k+1}=X_{i}^{k}+r_{3} \mathrm{o}\left(X_{p}^{k}-X_{i}^{k}\right)
$$

In which the $r_{3} \in R^{n}$ denotes a uniform random sequence within the range $(0,1)$. The members that are remaining (the rangers) will now range through the random walks (10 and 11): 


$$
\begin{aligned}
& X_{i}^{k+1}=X_{i}^{k}+l_{i} D_{i}^{k}\left(\varphi^{k+1}\right) \\
& \text { In which } l_{i}=a \cdot r_{1} l_{\max }
\end{aligned}
$$

\section{Support Vector Machine (SVM) based Classifier}

Initially SVM links all the input points within a high-dimensional feature space that consists of a nonlinear mapping function $\Phi$. It transmits it through linear classification or the regression in a high dimensional feature space.

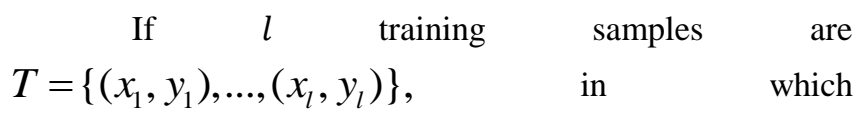
$x_{i} \in R^{n}, y_{i} \in\{1,-1\}$ (the classification) or the $y_{i} \in R$ (the regression), $i=1, \ldots, l$. Non-linear function is $k\left(x_{i}, x_{j}\right)=\varnothing\left(x_{i}\right) \varnothing\left(x_{j}\right)$. The SVM is implemented by solving the equations below (12).

$$
\begin{aligned}
& \min _{w, \xi_{i}, b}\left\{\frac{1}{2}\|w\|^{2}+c \sum_{i} \xi_{i}\right\} \\
& \text { s.t. } y^{i}\left(\Phi^{T}\left(X_{i}\right) w+b\right) \geq 1-\xi_{i} \quad \forall i=1, \ldots, n \\
& \xi_{i} \geq 0 \quad \forall i=1, \ldots, n
\end{aligned}
$$

(12)

The means of calculating the Lagrangian multipliers, these optimization problems may be transformed into its dual problem as per (13).

$$
\begin{aligned}
& \min _{\alpha} \sum_{i, j} \alpha_{i} \alpha_{j} y_{i} y_{j} k\left(x_{i}, y_{j}\right)-\sum_{i=1}^{l} \alpha_{i} \\
& \text { s.t. } y^{T} \alpha=0 \\
& 0 \leq \alpha_{i}<C, i=1, \ldots, l
\end{aligned}
$$

Once an optimum solution $a *, b *$ is obtained the decision function below is used for determining the class to which the sample will belong (14).

$$
f(x)=\operatorname{sgn}\left(\sum_{i=1}^{l} y_{i} \alpha_{i}^{*} K\left(x_{i}, x\right)+b^{*}\right)
$$

The precision of classification of an SVM model is calculated as in (15):

$$
\text { Accuracy }=\frac{\# \text { correctly predicted data }}{\# \text { total testing data }} \times 100 \%
$$

The Original and large scale data $\mathrm{D}$ has to be partitioned into some smaller data sections $\{\mathrm{D} 1, \cdots, \mathrm{Dn}\}$.

IG based method results presented. The algorithms book 35000 . The

\section{Average based}

\begin{tabular}{|c|c|c|}
\hline $\begin{array}{r}\text { Training } \\
\text { Percentage }\end{array}$ & $\begin{array}{c}\text { IG based } \\
\text { feature } \\
\text { selection }\end{array}$ & $\begin{array}{c}\text { GSO } \\
\text { based feature } \\
\text { selection }\end{array}$ \\
\hline $20 \%$ & 63.33 & 65.83 \\
\hline $40 \%$ & 67.92 & 69.58 \\
\hline $60 \%$ & 78.33 & 82.29 \\
\hline $80 \%$ & 81.25 & 87.29 \\
\hline
\end{tabular}

\section{RESULTS AND DISCUSSION}

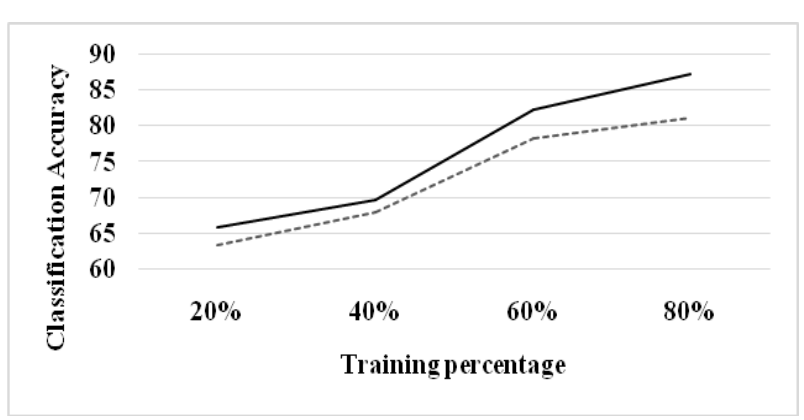

\section{IG Based feature selection}

Figure 1Average based

based $3.87 \%$ for $20 \%$ training, by $2.41 \% 4.93 \%$ $7.16 \%$ IG

Table 1Average Recall for GSO based Feature Selection

\begin{tabular}{|l|l|l|}
\hline & IG feature & Based \\
\hline & 634533 & 660967 \\
\hline & 6836 & 700967 \\
\hline & 786233 & 823567 \\
\hline & 815233 & 8738 \\
\hline
\end{tabular}

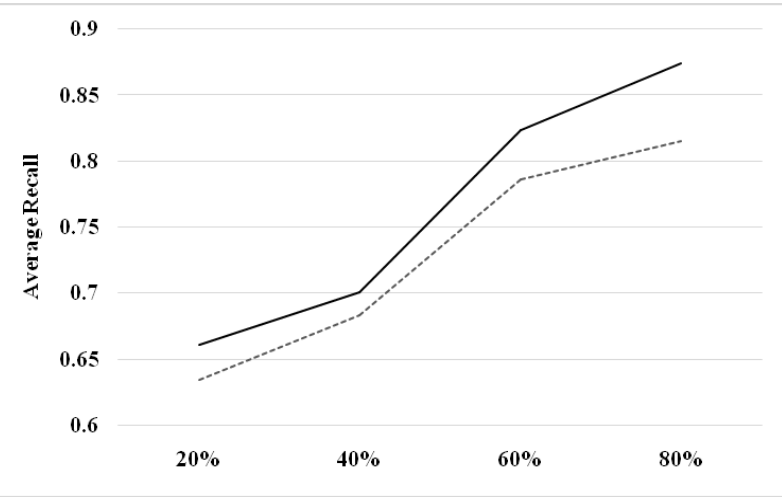

Figure 2Average based 
based $4.08 \% 2.5 \% 4.63 \% 6.93 \%$ IG.

\section{Average based}

\begin{tabular}{|c|l|c|}
\hline $\begin{array}{c}\text { Percent } \\
\text { age }\end{array}$ & $\begin{array}{c}\text { IG based } \\
\text { feature }\end{array}$ & $\begin{array}{c}\text { GSO based } \\
\text { feature selection }\end{array}$ \\
\hline & 6328 & 659267 \\
\hline & 680233 & 697633 \\
\hline & 782533 & 8213 \\
\hline & 811667 & 8715 \\
\hline
\end{tabular}

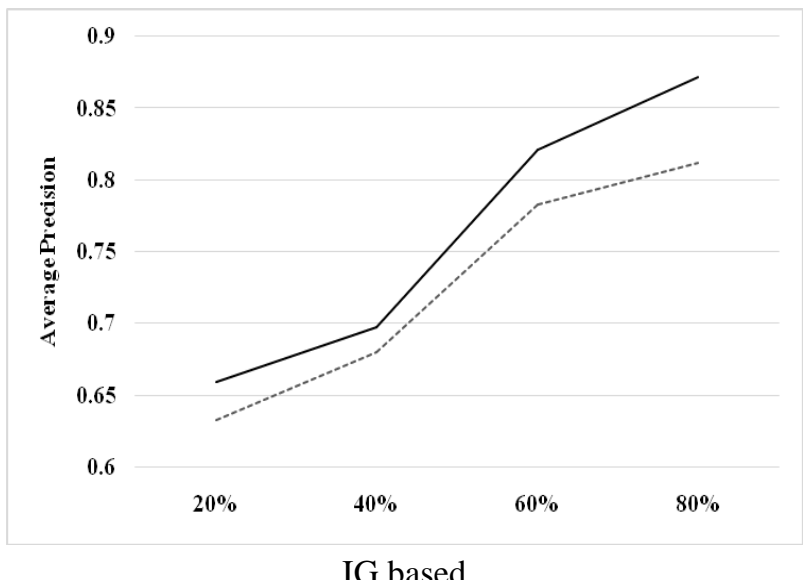

Figure 3Average based

based $4.09 \% 2.52 \% 4.83 \% 7.1 \% \mathrm{IG}$.

\section{Average based}

\begin{tabular}{|l|c|l|}
\hline $\begin{array}{c}\text { Percent } \\
\text { age }\end{array}$ & $\begin{array}{c}\text { IG based } \\
\text { feature }\end{array}$ & \\
\hline & 632067 & 657867 \\
\hline & 679067 & 6959 \\
\hline & 783467 & 821967 \\
\hline & 812633 & 8724 \\
\hline
\end{tabular}

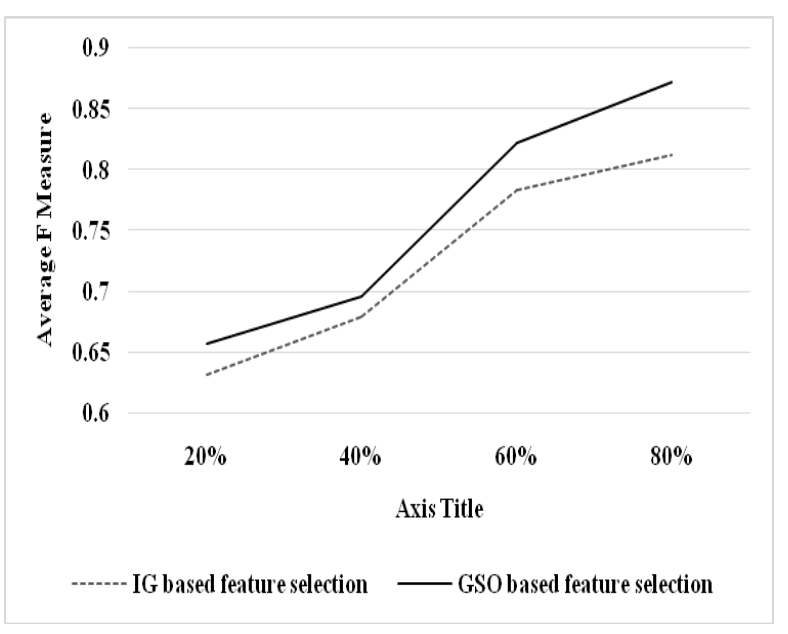

Figure 4Average based

based $4 \% \quad 2.44 \% \quad 4.79 \% \quad 7.09 \% \quad 80 \% \quad$ IG

\section{CONCLUSION}

Here, main focus in on the performance of the fast sentiment analysis to ensure that big data sets are efficiently handled. The classification of text that of the typical as it can include the discrimination that is based upon the opinion of the topic that is expressed. The selection of features will be a very significant aspect in sentiment analysis as according to the text that is opinionated. Here the IG and the GSO feature selection methods are proposed. The former is very popular as a filtering approach and the latter is a stochastic and evolutionary algorithm which mimics the animals and their foraging behaviour. For accomplishing this task there are many evolutionary algorithms that have been employed but they do not have good convergence speed. The GSO is quite efficient and can produce better speed of convergence. The selected feature set is used for classification using SVM. The parameter for the SVMs is a very critical task relating to efficiency and accuracy and the results have proved that this GSO based feature selection has a better accuracy by about $3.87 \%$ for the $20 \%$ training, by about $2.41 \%$ for the $40 \%$ training, by about $4.93 \%$ for the $60 \%$ training and by about $7.16 \%$ for the $80 \%$ training IG based

\section{REFERENCES}

1. Kumarave A., Rangarajan K.,Algorithm for automaton specification for exploring dynamic labyrinths,Indian Journal of Science and Technology,V-6,I-SUPPL5,PP-4554-4559,Y-2013

2. P. Kavitha, S. Prabakaran "A Novel Hybrid Segmentation Method with Particle Swarm Optimization and Fuzzy C-Mean Based On Partitioning the Image for Detecting Lung Cancer" International Journal of Engineering and Advanced Technology (IJEAT) ISSN: 2249-8958, Volume-8 Issue-5, June 2019

3. Kumaravel A., Meetei O.N.,An application of non-uniform cellular automata for efficient cryptography,2013 IEEE Conference on Information and Communication Technologies, ICT 2013,V-,I-,PP-1200-1205,Y-2013

4. Kumarave A., Rangarajan K.,Routing alogrithm over semi-regular tessellations,2013 IEEE Conference on Information and Communication Technologies, ICT 2013,V-,I-,PP-1180-1184,Y-2013

5. P. Kavitha, S. Prabakaran "Designing a Feature Vector for Statistical Texture Analysis of Brain Tumor" International Journal of Engineering and Advanced Technology (IJEAT) ISSN: 2249-8958, Volume-8 Issue-5, June 2019

6. Dutta P., Kumaravel A.,A novel approach to trust based identification of leaders in social networks, Indian Journal of Science and Technology,V-9,I-10,PP--,Y-2016

7. Kumaravel A., Dutta P.,Application of Pca for context selection for collaborative filtering,Middle - East Journal of Scientific Research,V-20,I-1,PP-88-93,Y-2014

8. Kumaravel A., Rangarajan K.,Constructing an automaton for exploring dynamic labyrinths,2012 International Conference on Radar, Communication and Computing, ICRCC 2012,V-,I-,PP-161-165,Y-2012

9. P. Kavitha, S. Prabakaran "Adaptive Bilateral Filter for Multi-Resolution in Brain Tumor Recognition" International Journal of Innovative Technology and Exploring Engineering (IJITEE) ISSN: 2278-3075, Volume-8 Issue-8 June, 2019

10. Kumaravel A.,Comparison of two multi-classification approaches for detecting network attacks, World Applied Sciences Journal,V-27,I-11,PP-1461-1465,Y-2013

11. Tariq J., Kumaravel A.,Construction of cellular automata over hexagonal and triangular tessellations for path planning of multi-robots,2016 IEEE International Conference on Computational Intelligence and Computing Research, ICCIC 2016,V-,I-,PP--,Y-2017

12. Sudha M., Kumaravel A.,Analysis and measurement of wave guides using poisson 
method,Indonesian Journal of Electrical Engineering and Computer Science, V-8,I-2,PP-546-548,Y-2017

13. Ayyappan G., Nalini C., Kumaravel A.,Various approaches of knowledge transfer in academic social network,International Journal of Engineering and Technology,V-,I-,PP-2791-2794,Y-2017

14. Kaliyamurthie, K.P., Sivaraman, K., Ramesh, S. Imposing patient data privacy in wireless medical sensor networks through homomorphic cryptosystems 2016, Journal of Chemical and Pharmaceutical Sciences 92.

15. Kaliyamurthie, K.P., Balasubramanian, P.C. An approach to multi secure to historical malformed documents using integer ripple transfiguration 2016 Journal of Chemical and Pharmaceutical Sciences 92

16. A.Sangeetha,C.Nalini,"Semantic Ranking based on keywords extractions in the web", International Journal of Engineering \& Technology, 7 (2.6) (2018) 290-292

17. S.V.GayathiriDevi,C.Nalini,N.Kumar,"An efficient software verification using multi-layered software verification tool "International Journal of Engineering \& Technology, 7(2.21)2018 454-457

18. C.Nalini,ShwtambariKharabe,"A Comparative Study On Different Techniques Used For Finger - Vein Authentication”, International Journal Of Pure And Applied Mathematics, Volume 116 No. 82017 , 327-333, Issn: 1314-3395

19. M.S. Vivekanandan and Dr. C. Rajabhushanam, "Enabling Privacy Protection and Content Assurance in Geo-Social Networks", International Journal of Innovative Research in Management, Engineering and Technology, Vol 3, Issue 4, pp. 49-55, April 2018.

20. Dr. C. Rajabhushanam, V. Karthik, and G. Vivek, "Elasticity in Cloud Computing", International Journal of Innovative Research in Management, Engineering and Technology, Vol 3, Issue 4, pp. 104-111, April 2018.

21. K. Rangaswamy and Dr. C. Rajabhushanamc, "CCN-Based Congestion Control Mechanism In Dynamic Networks", International Journal of Innovative Research in Management, Engineering and Technology, Vol 3, Issue 4, pp. 117-119, April 2018.

22. Kavitha, R., Nedunchelian, R., "Domain-specific Search engine optimization using healthcare ontology and a neural network backpropagation approach", 2017, Research Journal of Biotechnology, Special Issue 2:157-166

23. Kavitha, G., Kavitha, R., "An analysis to improve throughput of high-power hubs in mobile ad hoc network" , 2016, Journal of Chemical and Pharmaceutical Sciences, Vol-9, Issue-2: 361-363

24. Kavitha, G., Kavitha, R., "Dipping interference to supplement throughput in MANET", 2016, Journal of Chemical and Pharmaceutical Sciences, Vol-9, Issue-2: 357-360

25. Michael, G., Chandrasekar, A.,'Leader election based malicious detection and response system in MANET using mechanism design approach", Journal of Chemical and Pharmaceutical Sciences(JCPS) Volume 9 Issue 2, April - June 2016.

26. Michael, G., Chandrasekar, A.,"Modeling of detection of camouflaging worm using epidemic dynamic model and power spectral density", Journal of Chemical and Pharmaceutical Sciences(JCPS) Volume 9 Issue 2, April - June 2016.

27. Pothumani, S., Sriram, M., Sridhar, J., Arul Selvan, G., Secure mobile agents communication on intranet,Journal of Chemical and Pharmaceutical Sciences, volume 9, Issue 3, Pg No S32-S35, 2016

28. Pothumani, S., Sriram, M., Sridhar, Various schemes for database encryption-a survey, Journal of Chemical and Pharmaceutical Sciences, volume 9, Issue 3, Pg NoS103-S106, 2016

29. Pothumani, S., Sriram, M., Sridhar, A novel economic framework for cloud and grid computing, Journal of Chemical and Pharmaceutical Sciences, volume 9, Issue 3, Pg No S29-S31, 2016

30. Priya, N., Sridhar, J., Sriram, M. "Ecommerce Transaction Security Challenges and Prevention Methods- New Approach” 2016 ,Journal of Chemical and Pharmaceutical Sciences, JCPS Volume 9 Issue 3.page no:S66-S68

31. Priya, N.,Sridhar,J.,Sriram, M."Vehicular cloud computing security issues and solutions" Journal of Chemical and Pharmaceutical Sciences(JCPS) Volume 9 Issue 2, April - June 2016
32. Priya, N., Sridhar, J., Sriram, M. "Mobile large data storage security in cloud computing environment-a new approach" JCPS Volume 9 Issue 2. April - June 2016

33. Anuradha.C, Khanna.V, "Improving network performance and security in WSN using decentralized hypothesis testing "Journal of Chemical and Pharmaceutical Sciences(JCPS) Volume 9 Issue 2, April - June 2016 .

34. Anuradha.C, Khanna.V, "A novel gsm based control for e-devices" Journal of Chemical and Pharmaceutical Sciences(JCPS) Volume 9 Issue 2, April - June 2016.

35. Anuradha.C, Khanna.V, "Secured privacy preserving sharing and data integration in mobile web environments " Journal of Chemical and Pharmaceutical Sciences(JCPS) Volume 9 Issue 2, April - June 2016 .

36. Sundarraj, B., Kaliyamurthie, K.P. Social network analysis for decisive the ultimate classification from the ensemble to boost accuracy rates 2016 International Journal of Pharmacy and Technology 8

37. Sundarraj, B., Kaliyamurthie, K.P. A content-based spam filtering approach victimisation artificial neural networks 2016 International Journal of Pharmacy and Technology 83 .

38. Sundarraj, B., Kaliyamurthie, K.P. Remote sensing imaging for satellite image segmentation 2016 International Journal of Pharmacy and Technology 83 .

39. Sivaraman, K., Senthil, M. Intuitive driver proxy control using artificial intelligence 2016 International Journal of Pharmacy and Technology 84.

40. Sivaraman, K., Kaliyamurthie, K.P. Cloud computing in mobile technology 2016 Journal of Chemical and Pharmaceutical Sciences 92.

41. Sivaraman, K., Khanna, V. Implementation of an extension for browser to detect vulnerable elements on web pages and avoid click jacking 2016 Journal of Chemical and Pharmaceutical Sciences 9

\section{AUTHORS PROFILE}

Dr.K.P.Kaliyamurthie is self- directed, enthusiastic educator with a commitment on student development. He is with Bharath University, Chennai, Tamil Nadu, India as Professor and Dean of Computer Science and Engineering. 